\title{
The Neuroendocrine and Metabolic Outcomes of Bariatric Surgery Depend on Presurgical Control over Eating
}

\author{
José Ramón Muñoz-Rodríguez ${ }^{\mathrm{a}}$ Teresa Rodríguez-Cano $^{\mathrm{a}}$ Filomena Polo $^{\mathrm{a}}$ \\ Luis Sáenz-Mateos ${ }^{a}$ Andrea Agarrado ${ }^{a}$ Esperanza Segura $^{a}$ Gloria Casas $^{a}$ \\ Jesús Martín-Fernández ${ }^{\mathrm{a}}$ Luis Beato-Fernández ${ }^{\mathrm{a}} \quad$ Elisabet Salas ${ }^{\mathrm{a}}$ \\ Carmen González-Martín ${ }^{\mathrm{a}, \mathrm{b}}$ Luis F. Alguacil ${ }^{\mathrm{a}, \mathrm{b}}$

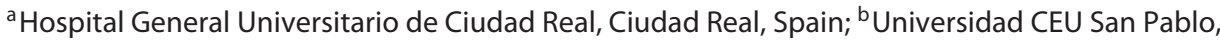 \\ Alcorcón, Madrid, Spain
}

\section{Keywords}

Eating control - Gastric bypass · Insulin resistance .

Brain-derived neurotrophic factor · Food craving

\begin{abstract}
Background: The outcomes of bariatric surgery are very irregular and mostly unpredictable. The search for variables of predictive value is encouraged to help preventing therapeutic failures. Objective: We aimed to confirm the hypothesis that preexisting eating behaviors could predict neuroendocrine and metabolic outcomes of gastric bypass surgery in morbidly obese subjects. Methods: Twenty-one morbidly obese patients from the Bariatric Surgery Program of our hospital were selected according to the specific inclusion and exclusion criteria for this study. The subjects filled out a validated questionnaire to quantify the "loss-of-control" (LC) dimension of food craving and provided serum samples at the onset of the study and 1 year after gastric bypass surgery. Hematological, metabolic, and hormonal variables were studied by conventional clinical tests and enzyme immunoassays and checked for correlations with LC both before and
\end{abstract}

\section{KARGER}

() 2019 S. Karger AG, Basel

E-Mail karger@karger.com

www.karger.com/nen after surgery. Results: Those patients that had exhibited worse eating control at the beginning of the study experienced a better metabolic response 1 year after surgery in terms of reduction of serum insulin, HOMA1-IR, HOMA2-IR, and vitamin $D_{1}$; all these variables were inversely correlated with presurgical LC. Serum brain-derived neurotrophic factor (BDNF) levels showed the same tendency; in fact, BDNF significantly decreased only in those patients with worse eating control. Conclusions: Problematic eating behaviors may predict a better response of insulin resistance and a specific reduction of serum BDNF in morbidly obese patients after gastric bypass surgery.

(c) 2019 S. Karger AG, Basel

\section{Introduction}

The outcomes of bariatric surgery are very diverse between patients and presently unpredictable; accordingly, the search for various kinds of variables of predictive value is encouraged to help preventing therapeutic failures [1]. It is generally accepted that patients with obesity and

\footnotetext{
Luis F. Alguacil

Facultad de Farmacia, Universidad CEU San Pablo

Urb. Montepríncipe

ES-28925 Alcorcón, Madrid (Spain)

E-Mail lfalguacil@ceu.es
} 
problematic eating behaviors, including dysregulated overeating, binge eating disorder, and "food addiction" [2], have dysregulated brain reward pathways [3] and/or disrupted cognitive processing of food cues [4], leading to a worse response to surgery when compared to other patients. Hence, established eating disorders such as binge eating disorder or bulimia nervosa are among the exclusion criteria for bariatric surgery in many hospitals, including ours. "Food-addicted" patients, as evaluated with the Yale Food Addiction Scale (YFAS), have been reported to experience lower rates of weight loss after surgery in some studies $[5,6]$ and, importantly, are supposed to be at increased risk of "addiction transfer" from compulsive food consumption to substance misuse [7]. The latter is an important issue, since the proportion of newonset substance users among bariatric patients after surgery has been estimated to range from 34.3 to $89.5 \%$ [8]. However, the evidence supporting these assumptions is far from conclusive. Thus, Ivezaj et al. [9] reviewed the literature to conclude that the presence of presurgical food addiction was not associated with postsurgical weight loss.

One of the possible sources of discrepancies between studies is the multidimensional nature of the food addiction construct and the YFAS; thus, if the predictive effect of problematic eating behaviors on surgery outcomes resides on a particular component of the scale, it could be masked by others to a different extent depending on the sample considered. Interestingly, one of the studies that found food addiction to be inversely related to weight loss after surgery simultaneously reported that binge eating tended to predict greater loss of excess weight in the same patients [6]. Similarly, when food craving questionnaires were used for this kind of studies, higher scores on the subscale "cues that may trigger food cravings" were associated with greater weight loss at short term after surgery, while higher scores on the subscale "guilt from cravings and/or giving into them" were associated with less weight loss [10].

That is why we had focused on a single factor such as "loss of control over eating" to phenotype our subjects in a previous study on eating behaviors in obesity [11]. Loss of control over eating can be defined as the subjective experience of being unable to control what or how much one eats, regardless of the amount of food consumed. It is a key factor of food craving in morbid obesity [12] that markedly resembles loss of control of drug use among drug addicts.

The present work is then aimed at establishing whether the metabolic and endocrinological status of obese pa-
Table 1. Main characteristics of the patients included in the study

\begin{tabular}{ll}
\hline Subjects (women:men), $n$ & $14: 7$ \\
Mean age \pm SEM, years & $43.7 \pm 2.7$ \\
Mean BMI \pm SEM, kg/m ${ }^{2}$ & $47.1 \pm 1.2$ \\
History of psychiatric disorders, \% & 28.6 \\
DM-2, \% & 23.8 \\
Hypertension, \% & 38.1 \\
Heart failure, \% & 9.5 \\
Dyslipidemia, \% & 4.8 \\
Hypothyroidism, \% & 9.5 \\
Reflux esophagitis, \% & 14.3 \\
Sleep apnea, \% & 23.8 \\
DDD/arthritis, \% & 23.8
\end{tabular}

BMI, body mass index; DM-2, diabetes mellitus type 2; DDD, degenerative disc disease.

tients is dependent on their control over eating, as well as the possible predictive value of loss of control with regard to the effects of gastric bypass surgery 1 year after the surgery. This time point is relevant for the early detection of biological changes that could translate into postoperative clinical problems later on, as we have suggested recently [11]. For this study, we collected diverse biochemical indicators and quantified serum neuropeptides and hormones widely known to regulate body weight in humans [13]; among the latter, we considered brain-derived neurotrophic factor (BDNF), a substance of marked interest since it has been specifically related to eating disturbances [14] and has recently been reported to decrease in the plasma of morbidly obese patients after surgery [15].

\section{Subjects and Methods}

\section{Subjects}

The patients of this study $(n=21)$ were selected from the Bariatric Surgery Program of the General University Hospital of Ciudad Real (Hospital General Universitario de Ciudad Real, HGUCR), Spain. All of them fit the requirements of the International Federation for the Surgery of Obesity and Metabolic Disorders (IFSO) to be considered for gastric bypass surgery.

The inclusion criteria were 5 years of maintained obesity, a body mass index (BMI) $>40 \mathrm{~kg} / \mathrm{m}^{2}$, an age of $18-60$ years, and psychological stability (at least 3 months free of anxiety, depression, impulse control disturbances, and other psychiatric symptomatology). The exclusion criteria were obesity secondary to endocrinopathies or drug treatments, a BMI $>60 \mathrm{~kg} / \mathrm{m}^{2}$ or a BMI $>55 \mathrm{~kg} /$ $\mathrm{m}^{2}$ and 1 or more significant comorbid conditions, antecedents of major psychiatric disease (psychosis, schizophrenia, bipolar disorder, and depression with a Beck Depression Inventory score $>21$ ), mental retardation, eating disorders (binge eating disorder, bulimia nervosa), and alcohol/drug abuse.
Muñoz-Rodríguez et al. 
Table 2. Items of the FCQ-T used to quantify "loss of eating control" (LC)
1. When I crave something, I know I won't be able to stop eating once I start

2. If I eat what I am craving, I often lose control and eat too much

3. If I get what I am craving I cannot stop myself from eating it

4. I have no will power to resist my food crave

5. Once I start eating, I have trouble stopping

6. If I give in to a food craving, all control is lost
The main characteristics and comorbidities of the patients are depicted in Table 1. Three subjects were medicated with oral antidiabetic drugs, 2 were on diuretics, 5 received other antihypertensives, 6 were on psychopharmaceuticals, and 4 received other, unspecified medications. The psychopharmaceuticals prescribed were selective serotonin reuptake inhibitors (SSRIs; fluoxetine at $20 \mathrm{mg} /$ day or sertraline at $50-100 \mathrm{mg} /$ day) as part of maintenance treatment for a previous symptomatology of anxiety/depression.

Prior to surgery, the participants provided a blood sample for biological analysis and completed a copy of the Spanish version of the State and Trait Food Cravings Questionnaire, trait scale (FCQT). As in previous studies [11], "loss of control" (LC) was captured from 6 selected questions of the FCQ-T scored from 1 ("never") to 6 ("always") and summed to calculate a final LC score (Table 2). The patients were then scheduled for gastric bypass surgery, and 1 year after the intervention, another blood sample was obtained to study the evolution of the hematological, biochemical, and endocrinological variables.

\section{Hematology and Biochemistry}

Collection and preparation of the biological samples, blood count, and most serum biochemical determinations in presurgical and postsurgical samples were performed according to conventional procedures routinely used in the Laboratory of Clinical Analysis of our hospital. Some aliquots of serum samples were sent to the Translational Research Unit to study hormones and neuropeptides with enzyme immunoassays (EIAs) or enzyme-linked immunosorbent assays (ELISAs) according to the manufacturer's protocols. The following kits were used: EZHADP-61K Human Adiponectin ELISA kit (Millipore, Billerica, MA, USA); CYT306 ChemiKine Brain Derived Neurotrophic Factor (BDNF) ELISA kit (Millipore); Human Cocaine- and Amphetamine-Regulated Transcript peptide (CART) EIA kit (RayBiotech, Norcross, GA, USA); EZGRT-89K Human Ghrelin ELISA kit (Millipore); EZHI-14K Human Insulin ELISA kit (Millipore); and EZHL-80SK Human Leptin "Dual Range” ELISA kit (Millipore).

\section{Statistical Analysis}

Statistical analyses were performed using SPSS software (version 19.0 for Windows; IBM, Armonk, NY, USA) and graphics with R Studio 1.0.143 (R Statistics, Vienna, Austria). Correlation analyses (Spearman's rho) were carried out to study possible associations of the different hormonal and biochemical variables with loss of control over eating, as quantified with the LC score.

Previously, a multiple linear regression analysis was applied to check the possibility that age, gender, and history of psychiatric disturbances/SSRI treatment could represent confounding variables that influenced the LC scores. Medications other than SSRIs were not included in this analysis, since they were prescribed to a too low number of patients to have influenced the results or they were not expected to produce significant changes in hormonal measurements bearing in mind their pharmacological profiles.

After correlation analysis, any significant positive correlation with LC score indicated that the variable considered was directly associated with loss of control since both variables showed a common increase, while a significant negative correlation indicated that the variable considered was inversely related to loss of control. Only those parameters that were significantly correlated with LC were further analyzed by two-way ANOVA (and Bonferroni post hoc test), with treatment status and eating control as independent variables; to achieve this, the patients were divided into two groups according to the median LC score (better control: LC $<15$; worse control: LC $\geq 15$ ) and two treatment statuses were considered: before surgery and after surgery. Statistical significance was always considered if $p<0.05$ with a $95 \%$ confidence interval.

\section{Results}

The multiple linear regression analysis showed that age, gender, and history of psychiatric disturbances/SSRI treatment only represented $22 \%$ of the variation in LC score $\left(R^{2}=0.22\right)$, which was nonsignificant $(p=0.226)$. Other than with iron level, LC score was not correlated with any other variable studied in the patients before surgery (Table 3 ). Gastric bypass surgery led to a marked reduction in BMI (from $47.1 \pm 1.2$ to $30.6 \pm 1.1 \mathrm{~kg} / \mathrm{m}^{2}, p<$ $0.05)$; this reduction represents a total body weight loss of $35.0 \pm 1.8 \%$ and an excess weight loss of $76.2 \pm 4.0 \%$. No new cases of negative eating behavior or addiction transfer were detected. A negative correlation was seen between preexisting LC score and postsurgical insulin recovery, HOMA1-IR, HOMA2-IR, vitamin $\mathrm{D}_{1}$, and BDNF values (Table 3).

Figure 1 puts together the pre- and postsurgical values of the latter variables for the patients with better and those with worse eating control as defined on the basis of the median LC score before surgery (see Subjects and Methods). As can be seen, both subgroups exhibited similar values at baseline, but the response to surgery (as expected from the analysis of correlations) was more marked among the patients with worse eating control concerning carbohydrate metabolism biomarkers; this applied to insulin levels ( $85 \%$ reduction in these patients vs. $64 \%$ in the 
Table 3. Biological variables studied in the patients before and after gastric bypass surgery and their correlations with loss of control (LC) scores

\begin{tabular}{|c|c|c|c|c|c|}
\hline \multirow[t]{2}{*}{ Variable } & \multirow[t]{2}{*}{ Unit } & \multicolumn{2}{|l|}{ Before surgery } & \multicolumn{2}{|l|}{ After surgery } \\
\hline & & mean $\pm \mathrm{SEM}$ & $\begin{array}{l}\text { LC } \\
\text { correlation }\end{array}$ & mean \pm SEM & $\begin{array}{l}\text { LC } \\
\text { correlation }\end{array}$ \\
\hline BMI & $\mathrm{kg} / \mathrm{m}^{2}$ & $47.24 \pm 1.22$ & 0.118 & $30.57 \pm 1.13^{* * *}$ & 0.315 \\
\hline Leukocytes & $($ cells $/ \mathrm{L}) \times 10^{9}$ & $7.81 \pm 0.41$ & -0.284 & $6.55 \pm 0.3^{*}$ & -0.018 \\
\hline Hemoglobin & $\mathrm{g} / \mathrm{dL}$ & $14.1 \pm 0.26$ & -0.086 & $13.71 \pm 0.41$ & 0.040 \\
\hline Creatinine & $\mathrm{mg} / \mathrm{dL}$ & $0.79 \pm 0.04$ & 0.206 & $0.68 \pm 0.03^{* *}$ & 0.078 \\
\hline Total proteins & $\mathrm{g} / \mathrm{dL}$ & $7.28 \pm 0.09$ & -0.231 & $7.04 \pm 0.09^{* *}$ & -0.059 \\
\hline GGT & $\mathrm{IU} / \mathrm{L}$ & $42.48 \pm 9.97$ & 0.025 & $19.43 \pm 3.39^{* * *}$ & 0.162 \\
\hline AST & $\mathrm{IU} / \mathrm{L}$ & $23.86 \pm 1.66$ & -0.138 & $21.95 \pm 1.69$ & 0.030 \\
\hline ALT & $\mathrm{IU} / \mathrm{L}$ & $29.76 \pm 2.5$ & 0.148 & $23.86 \pm 2.95^{*}$ & 0.113 \\
\hline CRP & $\mathrm{mg} / \mathrm{dL}$ & $1.35 \pm 0.35$ & -0.097 & $0.37 \pm 0.16^{* *}$ & -0.021 \\
\hline Total cholesterol & $\mathrm{mg} / \mathrm{dL}$ & $187.81 \pm 6.36$ & 0.240 & $174.62 \pm 7.16^{*}$ & -0.182 \\
\hline $\mathrm{HDL}$ & $\mathrm{mg} / \mathrm{dL}$ & $42.05 \pm 1.79$ & 0.108 & $55.29 \pm 3.18^{* * *}$ & -0.089 \\
\hline $\mathrm{LDL}$ & $\mathrm{mg} / \mathrm{dL}$ & $118.1 \pm 6.15$ & 0.314 & $98.24 \pm 5.89^{* *}$ & 0.037 \\
\hline Triglycerides & $\mathrm{mg} / \mathrm{dL}$ & $135.75 \pm 11$ & -0.098 & $90.19 \pm 7.11^{* * *}$ & 0.026 \\
\hline Glucose & $\mathrm{mg} / \mathrm{dL}$ & $110.42 \pm 3.04$ & 0.172 & $89.33 \pm 2.01^{* * *}$ & -0.139 \\
\hline HOMA1- $\beta$ & - & $258.87 \pm 36.91$ & -0.397 & $151.11 \pm 56.91^{* *}$ & -0.226 \\
\hline HOMA1-IR & - & $8.56 \pm 1.18$ & -0.303 & $1.78 \pm 0.43^{* *}$ & $-0.521^{\#}$ \\
\hline HOMA2- $\beta$ & - & $172.47 \pm 17.98$ & -0.422 & $100.11 \pm 19.94^{* *}$ & -0.252 \\
\hline HOMA2-IR & - & $4.05 \pm 0.5$ & -0.386 & $1.05 \pm 0.26^{* *}$ & $-0.474^{\#}$ \\
\hline Uric acid & $\mathrm{mg} / \mathrm{dL}$ & $6.11 \pm 0.32$ & 0.143 & $4.52 \pm 0.19^{* * *}$ & 0.081 \\
\hline Vitamin $\mathrm{D}_{1}$ & $\mathrm{ng} / \mathrm{mL}$ & $18.1 \pm 1.76$ & -0.119 & $25.13 \pm 2.22^{*}$ & $-0.434^{\#}$ \\
\hline Intact PTH & $\mathrm{pg} / \mathrm{mL}$ & $70 \pm 6.61$ & 0.184 & $55.83 \pm 5.59$ & 0.216 \\
\hline Phosphorus & $\mathrm{mg} / \mathrm{dL}$ & $2.89 \pm 0.1$ & -0.020 & $3.56 \pm 0.11^{* * *}$ & -0.139 \\
\hline Calcium & $\mathrm{mg} / \mathrm{dL}$ & $9.39 \pm 0.08$ & 0.021 & $9.49 \pm 0.09$ & -0.216 \\
\hline Magnesium & $\mathrm{mg} / \mathrm{dL}$ & $2.02 \pm 0.04$ & 0.313 & $2.06 \pm 0.03$ & -0.118 \\
\hline Iron & $\mu \mathrm{g} / \mathrm{dL}$ & $67.38 \pm 4.28$ & $0.472^{\#}$ & $88.05 \pm 7.91^{* *}$ & 0.303 \\
\hline Ferritin & $\mathrm{ng} / \mathrm{mL}$ & $98.99 \pm 16.74$ & 0.027 & $112.13 \pm 21.8$ & 0.138 \\
\hline Vitamin $B_{12}$ & $\mathrm{pg} / \mathrm{mL}$ & $410.56 \pm 38.02$ & 0.003 & $336.62 \pm 27.21$ & 0.290 \\
\hline Cortisol & $\mathrm{nmol} / \mathrm{dL}$ & $301.3 \pm 19.04$ & 0.110 & $311.9 \pm 27.67$ & 0.412 \\
\hline Adiponectin & $\mathrm{ng} / \mathrm{mL}$ & $24.37 \pm 4.52$ & 0.079 & $49.03 \pm 6.12^{* *}$ & 0.014 \\
\hline Ghrelin & $\mathrm{pg} / \mathrm{mL}$ & $189.68 \pm 25.3$ & -0.021 & $338.37 \pm 55.86^{*}$ & -0.236 \\
\hline Leptin & $\mathrm{ng} / \mathrm{mL}$ & $43.15 \pm 3.31$ & 0.221 & $11.42 \pm 2.32^{* * *}$ & -0.069 \\
\hline Insulin & $\mu \mathrm{U} / \mathrm{mL}$ & $29.91 \pm 4.19$ & -0.247 & $8.4 \pm 2.25^{* *}$ & $-0.470^{\#}$ \\
\hline BDNF & $\mathrm{ng} / \mathrm{mL}$ & $14.39 \pm 1.13$ & 0.083 & $12.23 \pm 1.04$ & $-0.465^{\#}$ \\
\hline CART & $\mathrm{ng} / \mathrm{mL}$ & $4.25 \pm 0.58$ & 0.152 & $3.16 \pm 0.29$ & -0.202 \\
\hline
\end{tabular}

Values were calculated from at least 17 determinations. LC, loss of control over eating; BMI, body mass index; GGT, $\gamma$-glutamyltransferase; AST, aspartate aminotransferase; ALT, alanine aminotransferase; CRP, C-reactive protein; HDL, high-density lipoprotein; LDL, low-density lipoprotein; HOMA, homeostatic model assessment; IR, insulin resistance; PTH, parathyroid hormone; BDNF, brain-derived neurotrophic factor; CART, cocaineand amphetamine-regulated transcript peptide. * Significant differences (bold type) with respect to presurgery values $\left({ }^{*} p<0.05,{ }^{* *} p<0.01,{ }^{* * *} p<0.001\right)$. ${ }^{*}$ Significant correlations (bold type) with LC score $\left({ }^{\#} p<0.05\right)$.

subgroup with better control), HOMA1-IR (90 vs. 71\%), and HOMA2-IR (87 vs. $65 \%$ ). The BDNF levels only varied in a significant manner $(25 \%$ reduction) in the patients with worse eating control, while a very marked increase in vitamin $\mathrm{D}_{1}$ level was only noted in the patients with better eating control.

\section{Discussion and Conclusion}

The results obtained in this study show that loss of control over eating does not influence the metabolic status of morbidly obese patients to a great extent, but it predicts a differential response to surgery. It seems that those 
Fig. 1. Pre- and postsurgical values of variables showing a significant correlation with loss of eating control (LC score) in patients or worse food control (WC; LC score $\geq 15$ ). Outliers are represented by dots. ${ }^{*} p<0.05$. with better food control (BC; LC score $<15)$
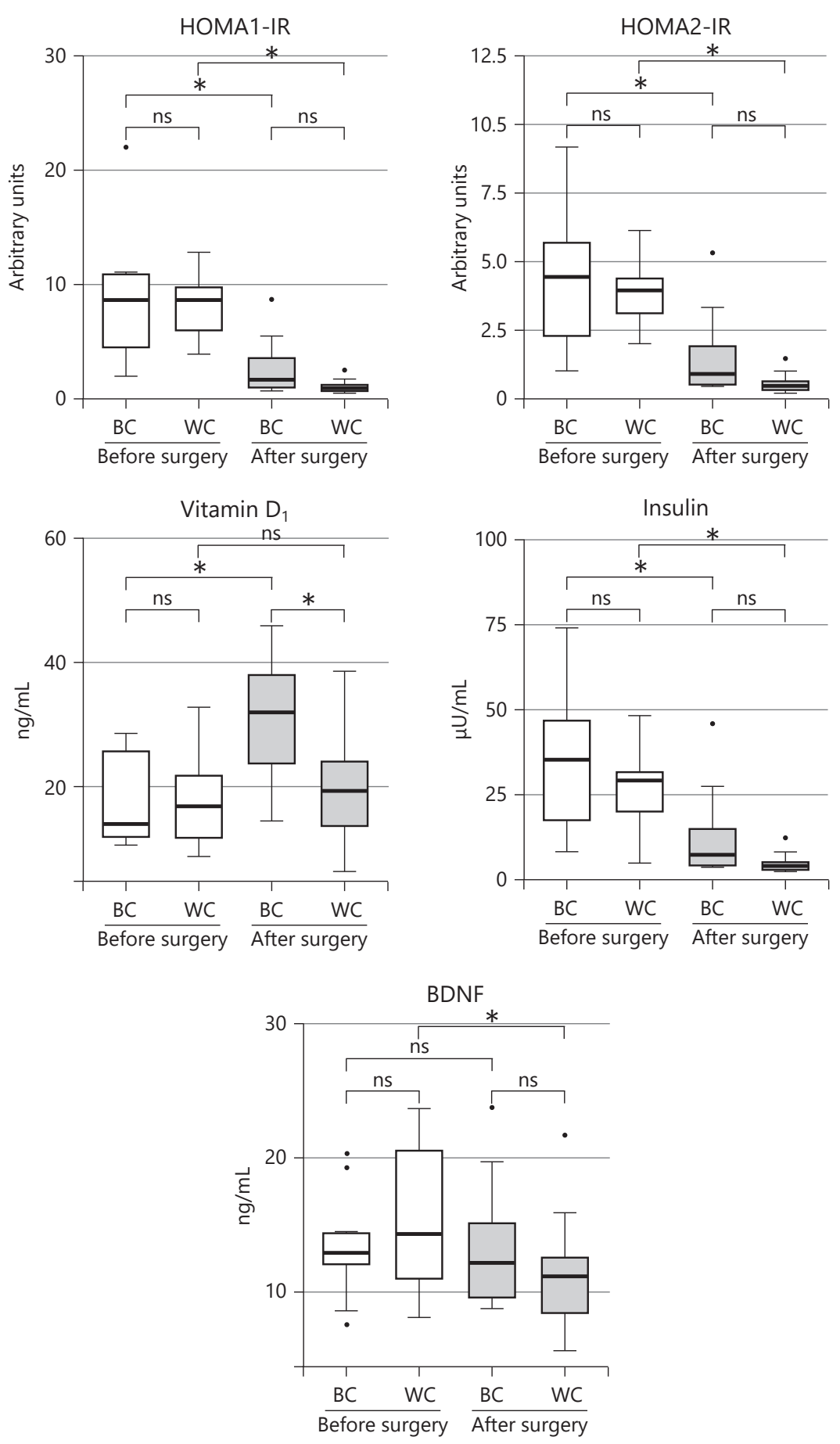

patients with worse control over eating (that is, those with higher LC scores) had improved their carbohydrate metabolism better 1 year after surgery (that is, they exhibited lower postsurgical insulin, HOMA1-IR, and HOMA2-IR values). These short-term differences must be reevaluated over longer periods of follow-up of gastric bypass surgery; however, they fit well with the hypothesis that the etiology of obesity could be more closely related to inadequate eating behaviors in those patients with better metabolic responses to therapeutic approaches partially based on 
limiting overeating (i.e., gastric bypass). Conversely, patients affected more by primary metabolic dysregulation than by problematic eating behaviors would benefit from restrictive surgery to a lesser extent, at least concerning metabolism. The opposite will be true concerning behavior: those patients with problematic eating behaviors will be at higher risk of psychological problems after surgery (i.e., "addiction transfer"), since comfort eating is no longer possible to the same extent as before the intervention [16].

The results obtained for BDNF are also compatible with the commented hypothesis and could also explain some apparently contradictory data found in the literature. Despite some findings of BDNF alterations in the serum of human obese patients, a direct relationship between obesity and BDNF levels tends to be discarded [17]. However, we have recently reported a significant BDNF decrease 1 year after gastric bypass surgery in morbidly obese patients [15]. None of the former studies considered the possibility that a differential eating behavior among obese individuals could be influencing the results. In fact, BDNF plasma levels have repeatedly been shown to be altered in eating control disorders, and the $B D N F$ gene itself is now considered one of the obesity-related genes more closely associated with the etiology of eating disorders [14]. Bearing in mind these preceding results, our present finding that postsurgical BDNF levels are inversely correlated with preexisting loss of control over eating strongly suggests that BDNF reduction could be detecting a short-term correction of problematic eating behaviors in our patients; however, the exact clinical meaning of these results needs to be specifically addressed. Interestingly, BDNF is widely known to play a key role in the neurobiology of drug craving [18], which further supports the importance of this neuropeptide as a putative biomarker of different kinds of addiction. As in the case of BDNF, the heterogeneity of obesity may underlie many apparent discrepancies found in the literature when trying to establish possible relationships between different variables and BMI values. Thus, for instance, the densities of striatal dopamine transporters and $\mathrm{D}_{2}$ receptors have been found to be negatively correlated with BMI in some studies $[19,20]$ but not in others $[21,22]$. These discrepancies could be explained by study differences in the proportion of obese subjects with inadequate eating behaviors, who are expected to exhibit altered dopaminergic transmission in brain reward areas similar to those exhibited by drug addicts according to the reward deficiency syndrome theory [23].
Our analysis revealed some other correlations which were much more difficult to interpret than those previously commented on. This was the case with the correlation between LC score and presurgical iron level, as well as with the negative correlation between LC score and postsurgical vitamin $\mathrm{D}_{1}$ level. On the basis of the data and the evidence presently available from the literature, any attempt to explain these associations could be highly speculative.

The main limitation of the present work is the low sample size. However, the results obtained are robust enough to strongly recommend extended work in the same direction, preferably focused on the evolution of carbohydrate metabolism and BDNF levels.

In conclusion, this study tends to show that morbidly obese patients may have different responses to bariatric surgery depending on preexisting eating control, the main differences applying to insulin resistance and serum BDNF levels. Further studies with higher numbers of patients and longer periods of follow-up are needed to confirm these findings and translate them into useful applications for health professionals.

\section{Acknowledgements}

The authors thank Amelia González-López for excellent technical assistance and Santiago Angulo Díaz-Parreño for statistical advice.

\section{Statement of Ethics}

The subjects gave their written informed consent. The study was approved by the Ethics Committee for Clinical Research (Comité Ético de Investigación Clínica, CEIC) of HGUCR, Spain. All procedures were in accordance with the ethical standards of the institutional and national research committees, as well as with the 1964 Helsinki Declaration and its later amendments.

\section{Disclosure Statement}

The authors have no conflicts of interest to declare.

\section{Funding Sources}

This work was supported by Fondo de Investigaciones Sanitarias, Instituto de Salud Carlos III, Spain (PI10/00440).
Muñoz-Rodríguez et al. 


\section{Author Contributions}

J.R.M.-R.: acquisition, analysis and interpretation of data, revision of the draft article; T.R.-C., F.P., and J.M.-F.: study design, revision of the draft article; L.S.-M., A.A., and E. Segura: acquisi- tion of data, revision of the draft article; G.C. and L.B.-F.: analysis of data, revision of the draft article; E. Salas and C.G.-M.: study design, acquisition of data, revision of the draft article; L.F.A.: study design, analysis and interpretation of data, drafting the manuscript.

\section{References}

1 Christensen BJ, Schmidt JB, Nielsen MS, Tækker L, Holm L, Lunn S, et al. Patient profiling for success after weight loss surgery (GO Bypass study): an interdisciplinary study protocol. Contemp Clin Trials Commun. 2018 Feb;10:121-30.

2 Davis C, Curtis C, Levitan RD, Carter JC, Kaplan AS, Kennedy JL. Evidence that 'food addiction' is a valid phenotype of obesity. Appetite. $2011 \mathrm{Dec} ; 57(3): 711-7$.

3 Berthoud HR, Lenard NR, Shin AC. Food reward, hyperphagia, and obesity. Am J Physiol Regul Integr Comp Physiol. 2011 Jun; 300(6):R1266-77.

4 Higgs S. Cognitive processing of food rewards. Appetite. 2016 Sep;104:10-7.

5 Holgerson AA, Clark MM, Ames GE, Collazo-Clavell ML, Kellogg TA, Graszer KM, et al. Association of adverse childhood experiences and food addiction to bariatric surgery completion and weight loss outcome. Obes Surg. 2018 Nov;28(11):3386-92.

6 Miller-Matero LR, Bryce K, Saulino CK, Dykhuis KE, Genaw J, Carlin AM. Problematic eating behaviors predict outcomes after bariatric surgery. Obes Surg. 2018 Jul;28(7): 1910-5.

7 Reslan S, Saules KK, Greenwald MK, Schuh LM. Substance misuse following Roux-en-Y gastric bypass surgery. Subst Use Misuse. 2014 Mar;49(4):405-17.

8 Li L, Wu LT. Substance use after bariatric surgery: a review. J Psychiatr Res. 2016 May;76: $16-29$

9 Ivezaj V, Wiedemann AA, Grilo CM. Food addiction and bariatric surgery: a systematic review of the literature. Obes Rev. 2017 Dec; 18(12):1386-97.
10 Crowley NM, LePage ML, Goldman RL, O’Neil PM, Borckardt JJ, Byrne TK. The Food Craving Questionnaire-Trait in a bariatric surgery seeking population and ability to predict post-surgery weight loss at six months. Eat Behav. 2012 Dec;13(4):366-70.

11 Rodríguez-Rivera C, Pérez-García C, MuñozRodríguez JR, Vicente-Rodríguez M, Polo F, Ford RM, et al. Proteomic identification of biomarkers associated with eating control and bariatric surgery outcomes in patients with morbid obesity. World J Surg. 2019 Mar; 43(3):744-50.

12 Crowley N, Madan A, Wedin S, Correll JA, Delustro LM, Borckardt JJ, et al. Food cravings among bariatric surgery candidates. Eat Weight Disord. 2014;19(3):371-6.

13 Moehlecke M, Canani LH, Silva LO, Trindade MR, Friedman R, Leitão CB. Determinants of body weight regulation in humans. Arch Endocrinol Metab. 2016 Apr;60(2):152-62.

14 Gervasini G, Gamero-Villarroel C. Discussing the putative role of obesity-associated genes in the etiopathogenesis of eating disorders. Pharmacogenomics. 2015;16(11):1287305.

15 Muñoz-Rodríguez JR, Agarrado A, MartínFernández J, Salas E, González-Martín C, Alguacil LF. Cocaine and amphetamine regulated transcript and brain-derived neurotrophic factor in morbid obesity. One-year follow-up after gastric bypass. Surg Obes Relat Dis. 2018 Nov;14(11):1732-9.

16 Yoder R, MacNeela P, Conway R, Heary C. How do individuals develop alcohol use disorder after bariatric surgery? A grounded theory exploration. Obes Surg. 2018 Mar;28(3): 717-24.
17 Saito S, Watanabe K, Hashimoto E, Saito T. Low serum BDNF and food intake regulation: a possible new explanation of the pathophysiology of eating disorders. Prog Neuropsychopharmacol Biol Psychiatry. 2009 Mar;33(2): 312-6.

18 Koskela M, Bäck S, Võikar V, Richie CT, Domanskyi A, Harvey BK, et al. Update of neurotrophic factors in neurobiology of addiction and future directions. Neurobiol Dis. 2017 Jan;97 Pt B:189-200.

19 Wang GJ, Volkow ND, Thanos PK, Fowler JS. Similarity between obesity and drug addiction as assessed by neurofunctional imaging: a concept review. J Addict Dis. 2004;23(3): 39-53.

20 Chen PS, Yang YK, Yeh TL, Lee IH, Yao WJ, Chiu NT, et al. Correlation between body mass index and striatal dopamine transporter availability in healthy volunteers - a SPECT study. Neuroimage. 2008 Mar;40(1):275-9.

21 Eisenstein SA, Antenor-Dorsey JA, Gredysa DM, Koller JM, Bihun EC, Ranck SA, et al. A comparison of $\mathrm{D} 2$ receptor specific binding in obese and normal-weight individuals using PET with (N-[(11)C]methyl)benperidol. Synapse. 2013 Nov;67(11):748-56.

22 van de Giessen E, Hesse S, Caan MW, Zientek F, Dickson JC, Tossici-Bolt L, et al. No association between striatal dopamine transporter binding and body mass index: a multi-center European study in healthy volunteers. Neuroimage. 2013 Jan;64:61-7.

23 Blum K, Febo M, Badgaiyan RD, Demetrovics Z, Simpatico T, Fahlke C, et al. Common neurogenetic diagnosis and meso-limbic manipulation of hypodopaminergic function in reward deficiency syndrome (RDS): changing the recovery landscape. Curr Neuropharmacol. 2017;15(1):184-94. 